\title{
Gas radon emission related to geodynamic activity on Mt. Etna
}

\author{
Giuseppina Immè $\left({ }^{1}\right)$, Santo La Delfa $\left({ }^{2}\right)\left({ }^{3}\right)$, Salvatore Lo Nigro $\left({ }^{1}\right)$, \\ Daniela Morelli $\left({ }^{1}\right)$ and Giuseppe Patanè ${ }^{2}$ ) \\ (') Dipartimento di Fisica e Astronomia, Università degli Studi di Catania, Italy \\ ${ }^{2}{ }^{2}$ Dipartimento di Scienze Geologiche, Università degli Studi di Catania, Italy \\ $\left(^{3}\right)$ IRMA srl, Istituto di Ricerca Medica e Ambientale, Acireale (CT), Italy
}

\begin{abstract}
We report preliminary observations on possible correlations between anomalies of subsoil radon concentration and geodynamical events on Mt. Etna. In recent years several studies have been carried out on radon as a precursor of geophysical events, most of them performed either on tectonic or volcanic areas. The peculiarity of our investigation lies on the choice of the etnean region, in which tectonic and volcanic features are both present. In order to characterize Mt. Etna features by investigating radon gas in soil, two stations were located along the NE-SW direction on Mt. Etna. Each of the two stations is fitted with a radon detector, a 3D seismic station and a meteorological station. Differences in the radon concentration trend in the data from north and south flanks could be linked to different faulting mechanisms and then to different mechanisms of radon uprising. The increase in soil radon concentration could be related to both seismic and volcanic events.
\end{abstract}

Key words radon - geodynamical precursor Mt. Etna

\section{Introduction}

The release of radon from natural minerals has been known since the 1920s and it depends on the activity concentrations of ${ }^{226} \mathrm{Ra}$ in the earth's crust, soil, rock and water. Radon monitoring has recently been used as a possible tool for earthquake prediction.

The origin and mechanisms of radon anomalies and their relationship to earthquakes is poorly understood, although several experiments, mathematical modelling and in situ hydraulic experiments have been performed (Sing

Mailing address: Dr. Daniela Morelli, Dipartimento di Fisica e Astronomia, Università degli Studi di Catania, Via S. Sofia 64 (Cittadella Universitaria), 95123 Catania, Italy; email: daniela.morelli@ct.infn.it et al., 1991; Virk et al., 1994; Virk, 1995; Al-Hilal et al., 1998). The observed radon anomalies correlated with geophysical events may be considered as having two possible origins. Either it is produced at and comes from a deep source or it is only locally displaced by other pore fluids whose motion is triggered by geodynamic events. In order to explain radon anomalies and geophysical events several models have been proposed. Sing (Sing et al., 1991) and Planinič (Planinič et al., 2001) suggested that the radon anomalies were related to mechanical crack growth in the rocks or to changes in flow rate of groundwater. This may allow either an opening of new cracks, a widening or closing of old cracks or a redistribution of opened and closed cracks. The diffusion coefficient of radon in the rocks will then be significantly changed, determining a change in the amount of radon which will escape from the rocks.

An alternative mechanism is the stress corrosion theory, first proposed by Anderson and Grew (Sing et al., 1991). It attributes the radon 
anomalies to slow crack growth controlled by stress corrosion. The mechanism of stress corrosion suggests that the occurrence of radon anomalies may depend on strain rate and local conditions.

Moreover, according to the compression mechanism proposed by King (Sing et al., 1991), the anomalous radon concentration may be due to an increase in crustal compression, impending an earthquake, that squeezes out the soil-gas into the atmosphere at an increased rate.

In volcanic areas (Monnin et al., 1991) a mechanism invoked to account for variation of radon concentration in soil is linked to an increased heat flow or dry steam discharge that would push up the available underground radon. Another hypothesis is that increased radon activity in the soil is due to the collapse of pores volume and the following up flow of deeper radon-rich ground gas.

The present study investigated an area in which tectonic and volcanic features are both present. Continuous measurements of radon, environmental parameters and seismic signals were recorded, studying the possible correlation between radon anomalies and geophysical events.

\section{Sites of investigation}

The Etnean area is characterized by tectonic structures. The sites where we located two stations were chosen considering the most active faults. In the Etnean area several fault systems became very active before and sometimes during eruptive events. The most extended among the cropping up structural discontinuities was chosen, which lies along the NE-SW direction through the volcano. The first site (Biancavilla) is in the SW flank, the second (Vena-Piedimonte Etneo) in the NE flank. Several researchers (Benina et al., 1984; Patanè et al., 1995) have observed that the fault segment in the South West Mt. Etna sector, becomes significantly seismically active when an eruptive event is coming; instead the segment in the NE sector and in the Valle del Bove valley shows a seismicity at less energy, however it is the site of sometimes very dangerous eruptions for the neighbouring vil- lages (for example the 1928 eruption that destroyed the Mascali village).

Figure 1 shows a view of the fault system, where it can be noted that the set of faults, which characterizes the south-western flank near Biancavilla (where the first station is located) represents the extension, along the NESW direction, of north-eastern fault-system of the Naca and Piedimonte area (in which the second station is located).

\subsection{Biancavilla station}

The station is located at about $1111 \mathrm{~m}$ a.s.l., between Biancavilla and Ragalna, in a region in which the Biancavilla fault and the Ragalna fault are predominant (Romano, 1982).

The Biancavilla faults, close to the site, are small ground fractures with prevailing NESW strike (Patanè and Imposa, 1996). They have been reported as faulting effects of the earthquake on 27th March 1983 (Azzaro, 1999). Extensional movements with small vertical displacements were observed in the locality of Calcerana; the occurrence of a secondary set of cracks trending in the NW-SE direction seems also to suggest left-lateral components (Azzaro, 1999).

The Ragalna fault is in the NE-SW direction between Santa Maria di Licodia and Ragalna East villages. The first evidence occurred in connection with the Santa Maria di Licodia earthquake in May 1898 (Azzaro, 1999). Discontinuous cracks along NE-SW direction develop in a narrow extent up to $300 \mathrm{~m}$ in length at the southern side of Ragalna east village. This fault is less active than the Biancavilla one. The frequent seismicity along the trend suggests that the Ragalna fault is partially hidden and has a longer development, at least $2.5 \mathrm{~km}$ more than its morphological evidence would indicate (Barbano et al., 1980; Azzaro, 1999).

\subsection{Vena station}

The station is located in Vena (a village near Piedimonte) at about $740 \mathrm{~m}$ a.s.l. (Romano, 1982). 


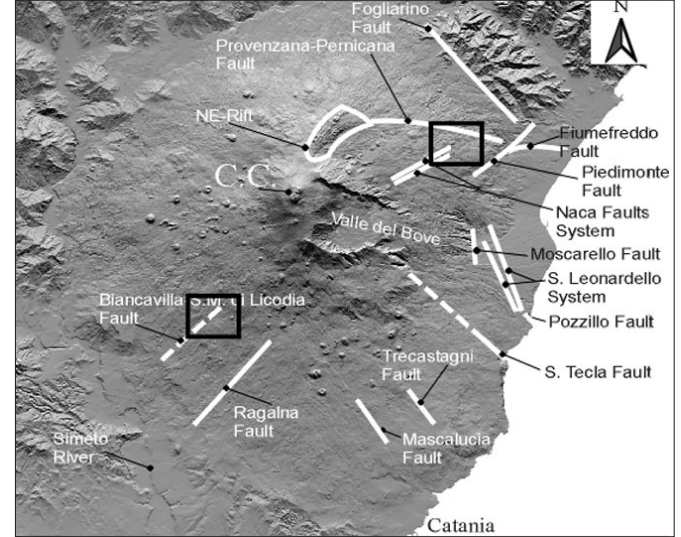

Fig. 1. Map of the sites location: SW Biancavilla; NE Vena (Piedimonte Etneo) and fault-system in the Etna region.

The structural belt system is that of the Naca and Piedimonte fault-system. On the basis of its morphostructural aspects, this highly tectonic area can be divided into two structurally linked systems where the NE-SW trend is always the tectonically dominant one.

In fact, the whole north-eastern flank of the Etnean complex is characterized by disturbances in that orientation, in particular along a strip developing almost continuously by the Naca and Piedimonte fault-system.

The Naca fault system is a couple of subparallel step faults facing the southeast with an overall extent of about $200 \mathrm{~m}$. They give rise to escarpments, locally called Ripe della Naca, dislocated by minor faults running $\mathrm{N}-\mathrm{S}$. The eruptive events of 1928 were associated with this system, originating from effusive cracks along one of the main fault lines.

The Piedimonte fault system is the repetition at NE of the Naca fault system of the dominant NE-SW trend. It is an step fault between Piedimonte and Fiumefreddo, variously dislocated by faults on NW-SE average trend; the most developed of these partly coincides with the upper course of the Fogliarino River.

The structural trend of the defined Naca and Piedimonte fault-system is dislocated by minor faults generally running WNW-ESE.
The main faults are in steps facing the east. The trend can be considered one of the most important elements for interpreting correctly the structural pattern of the volcano. In fact the swarm of eruptive cracks characterizing the northern slope of the Valle del Bove and the southern area of Piano Provenzano can be correlated with that trend. It is particularly interesting to observe that the disturbances connected with the trend appear dislocated on the north-eastern flank by transverse faults along the NW-SE trend. Locally these faults seem to show large strike-slip movement. The division of the structural trend into the above described two systems is probably connected with a disturbance having a NW-SE trend, completely covered by the Scorciavacca lavas and therefore with no in situ evidence to support it (Lo Giudice et al., 1982).

\section{Experimental devices}

Usually radon measurements, especially in inaccessible zones, are performed by means of solid-state nuclear track detectors, but these can give only integrated results and they need a frequent substitution to read the tracks. We preferred an active device, with sampling of soil gas into the detecting instrument. The choice of an active detection allowed radon monitoring for short time periods and both short and longterm analysis.

In particular we performed continuous measurements of soil radon concentrations using a portable system that uses an ionization chamber to detect alpha-particles from Radon decay.

The drawing system of soil gas consists of a drilling rod with an exchangeable drilling tip, with air-lock closed by a rivet and a capillary probe. The drilling rod is driven into the ground and a capillary probe is inserted into the drilling rod, the highest part of the capillary probe is connected to a filter in order to eliminate the moisture, then to a progeny filter that allows the ${ }^{222} \mathrm{Rn}$ pass only. The system is connected to the ionization chamber by means of a pump. Counting time was $10 \mathrm{~min}$, flow rate $0.05 \mathrm{l} / \mathrm{min}$, and the probe was driven into the soil at $1 \mathrm{~m}$ depth to reduce meteorological influence. 
The seismic station is composed of a three directional $1 \mathrm{~Hz}$ seismometer connected with a portable digital acquisition data system and a GPS time signal receiver. The GPS gives the time indication relative to the Universal time.

\section{Experimental results}

Measurements started on July 2001 and they are still in progress. The period of investigation has been characterized by geodynamical instability, in fact, two eruptive events occurred: the July-August 2001 and the October 2002January 2003 eruptions. Since we started measurements just when the first eruption began it has not been possible to determine the background value of radon concentration, namely radon concentration recorded in a quiescent period, to take as a reference level. However, we can compare the radon concentration values during the eruptive phenomena, and in the interval between them.

Figures 2 and 3 report the daily averages of radon concentration obtained at the southwestern and north-eastern stations respectively. The trend of the barometric pressure, the most influential meteorological parameter, is also reported.

The first evidence from our results is the different behaviour of radon concentration shown at the two flanks, corresponding to Vena and Biancavilla sites. First of all, while in the Vena station the values are always higher than $9000 \mathrm{Bqm}^{-3}$, in the Biancavilla one they do not exceed the value of $8000 \mathrm{Bqm}^{-3}$. The different behaviour is not due to different kinds of soil, in fact it consists, in both sites, of lava and volcanic ash in alternated layers, moreover the uranium content is the same in both sites, as observed by means of a previous gamma spectrometry investigation of the soil. Moreover the comparison with the barometric pressure trend, the same happens for the other meteorological parameters, indicates that the radon trend cannot be related to the meteorological trend: even if the atmospheric conditions are the same in both sites the radon concentration trend is opposite. The differences could be originated by the different way in which the dislocations in the two fault segments under investigation occur. In fact in the south-western sector, where the fault system has a tectonic origin, the earthquake fault plane solutions are related to horizontal strike-slip mechanisms, instead in the north-eastern flank, where both tectonical and volcanic behaviours are present. The earthquake fault plane solutions could also be associated to dip-slip mechanisms or to widening of the eruptive fractures (Montalto et al., 1996; Patanè et al., 1996; La Delfa et al., 1999; Vinciguerra et al., 1999). That could determine different mechanisms of radon uprising, as this is made easier in the north-eastern sector where the permeability is higher due to the enlarged fracturations, where in the recent past several eruptions occurred (Timpe della Naca 1928).

Our aim was to investigate the correlations between earthquakes and radon concentration in the Etnean area. Several studies conducted in tectonic areas disclosed a relation to earthquakes of magnitude larger than 3 (Virk et al., 1994; Igarashi et al., 1995; Al-Hilal et al., 1998). The Etnean area is characterized by a large number of earthquakes, up to thousands per day before an eruptive period (Benina et al., 1984; Patanè et al., 1995), but with low magnitude $(<3)$ and rarely they exceed magnitude 4 . Moreover Mt. Etna has a very complex structure, due to the occurrence of both tectonical and volcanic phenomena, so it is difficult to correlate radon anomalies and seismic events or volcanic phenomena. If we look at the NE flank radon concentration trend (fig. 3) we can distinguish an anomaly in the radon behaviour: concentration values start to increase on 27th October 2002, reach a maximum on 1st November 2002 and a minimum on 3rd November 2002. During this period several earthquakes of magnitude higher then 3 occurred, some of them reached values up to $M_{d} 4.5$ (29th October 2002 time 09:02:00 epicentral area of Santa Venerina). In order to find possible relations in a period between 1st September 2002 and 30th November 2002 that includes the eruption beginning (27th October 2002), we plotted (fig. 4) the trend of radon concentration together with the daily rate of earthquakes and the strain release. The latter was calculated for each event by means of the following relations (Patanè et al., 1995): 


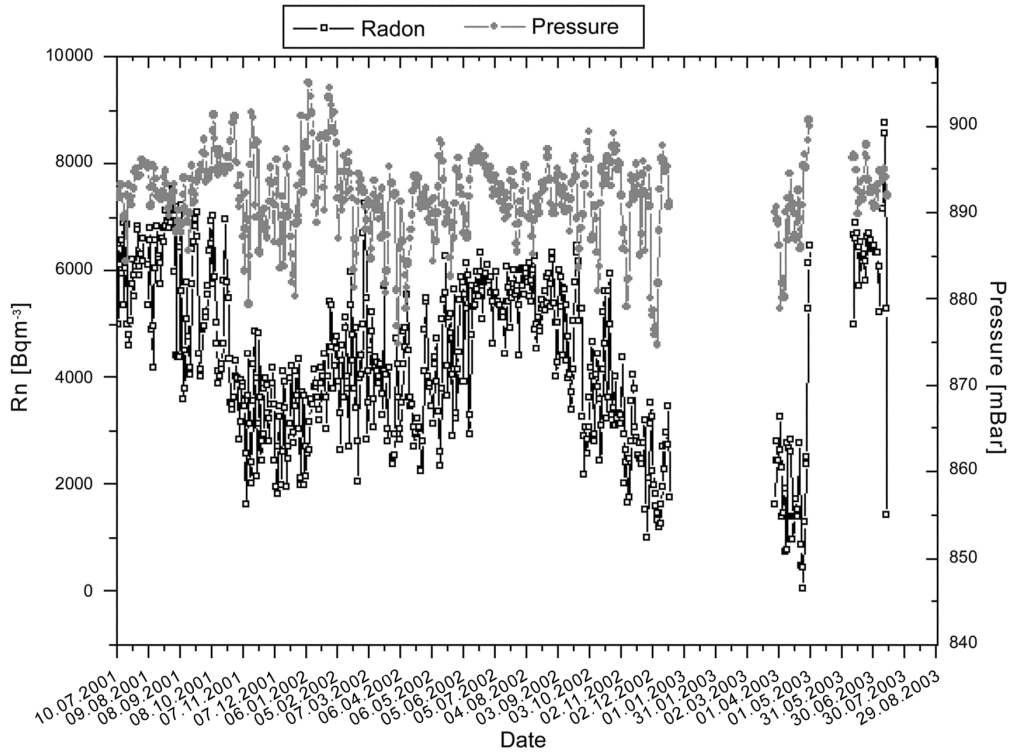

Fig. 2. Daily means of Radon concentration (open square) and of atmospheric pressure (full circle) in the Biancavilla site; July 2001-September 2003.

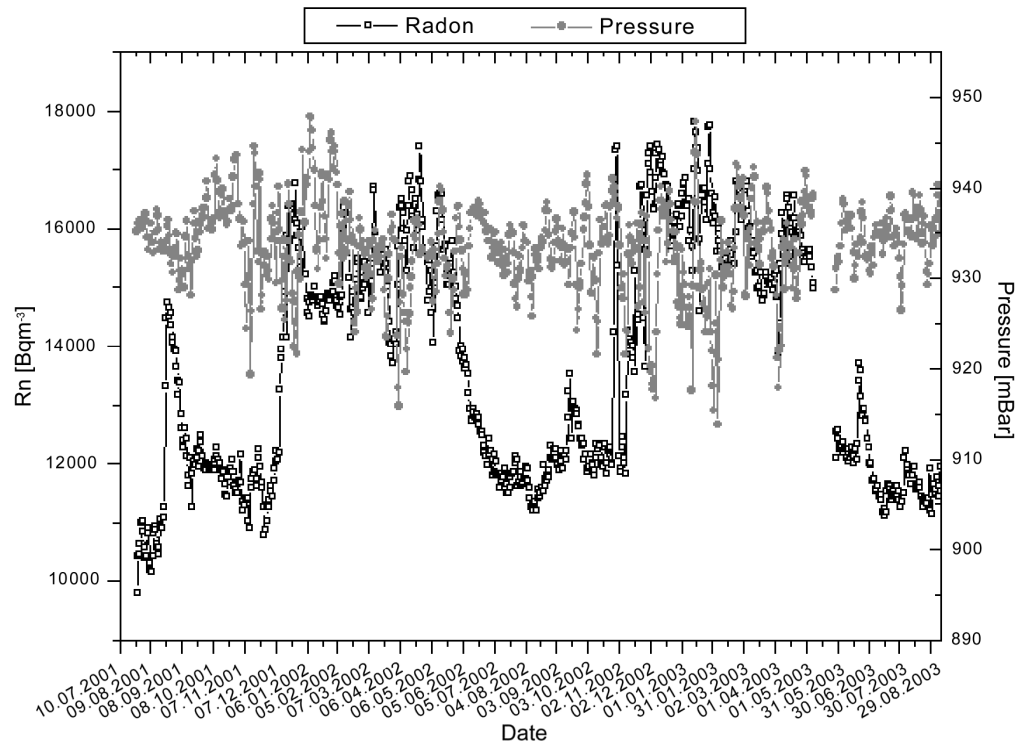

Fig. 3. Daily means of Radon concentration (open square) and of atmospheric pressure (full circle) in the Vena site; July 2001-September 2003. 


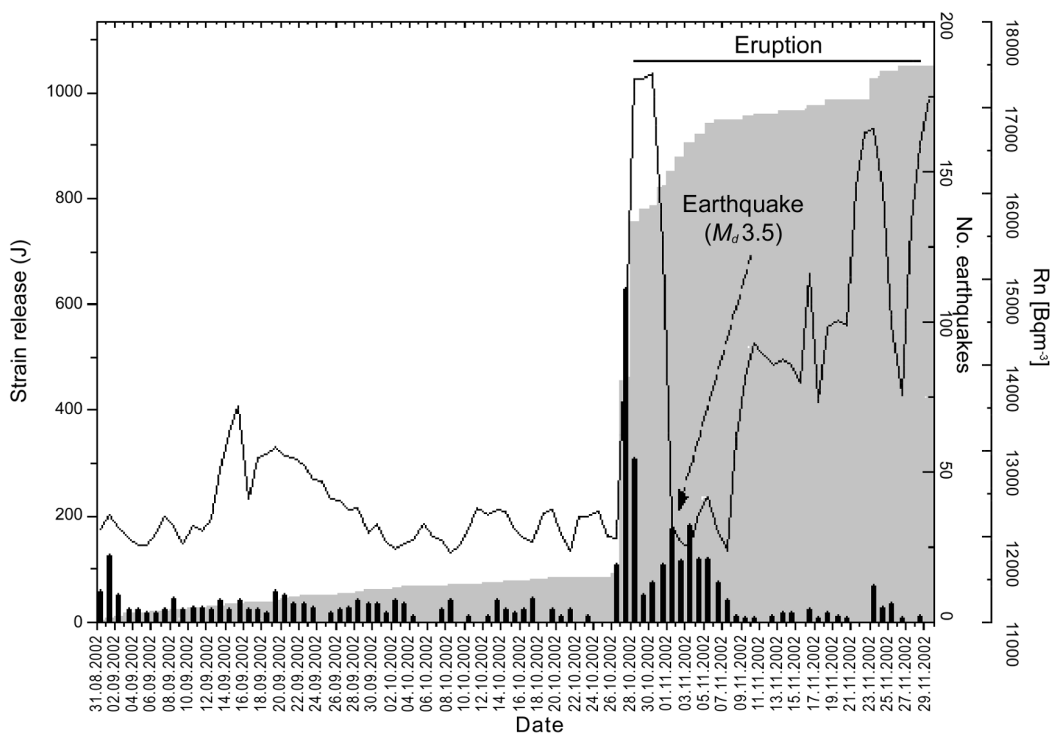

Fig. 4. Radon concentration (black line), daily earthquakes rate (black column bar) and strain release (grey histogram) measured in the period between 1st September 2002 and 30th November 2002 (Vena station).

$$
\begin{aligned}
& M_{\text {WAeq }}=\log \left[2800 \mu_{\max } / R(\theta, \varphi)\right]+ \\
& -0.35+0.17 \log \Delta_{\text {VEN }}
\end{aligned}
$$

where $M_{\text {WAeq }}$ is the earthquake magnitude WoodAnderson equivalent, $\mu_{\max }$ is the maximum peak amplitude (in $\mathrm{mm}$ ) at Vena station, $R(\theta, \varphi)$ is the radiation pattern for $S H$-waves, $\Delta_{\text {VEN }}$ is the distance between the station and the hypocentre; and

$$
\log E_{R i}=2.9+1.9 M_{\text {WAeq }}-0.024 M_{\text {WAeq }}^{2}
$$

where $E_{R i}$ is the energy determined from the formula of Richter (Richter, 1958), then the strain release is $\sqrt{E_{R i}} \cdot \Delta_{\text {VEN }}$ was determined by means o correspondence between the $S$ - $P$ time interval $\left(T_{S-P}\right)$ read on the seismograms and the hypocentral distance recorded in Vena during the 19911993 eruption; approximately at $T_{S-P} \approx 1 \mathrm{~s} \Delta_{\mathrm{VEN}}$ of $4 \mathrm{~km}$ corresponds (Patanè et al., 1995).

From fig. 4 we can observe that, as well as the radon rises the earthquake daily rate and strain release rise correspondingly at the eruption beginning.

By a first analysis we cannot confirm that the radon gas is a seismic event precursor except for only some local events. In fact, in this study we focused on 3rd November event with $M_{d} 3.5$, because the epicentral zone was close (less then 1 $\mathrm{km}$ ) to the Vena station (NE station) and because it occurred just after the radon anomaly (fig. 3), and is associated with evident soil fractures.

According to the observations, it is more appropriate to extend the investigation to the volcanic aspects, in particular to the eruption which started on 27th October 2002, that involved all the geostructures chosen for our investigation. If we then look at the radon trend recorded in the NE flank, under the hypothesis of volcanic activity, we can explain that the plateau region of higher radon activity (December 2001-May 2002) could indicate a relation with the magma uprising. The magma, moving inside the subsoil, could have induced a larger convection of radon gas owing to the increasing subsoil temperature, that could facilitate the gas escaping from the rocks.

Previous studies in volcanic areas (El Chichon volcano and Krafla volcano; Monnin and Seidel, 1991) have shown that radon measurements in the ground could be used as a precursor signal of eruptive phases. 


\section{Conclusions}

We have monitored radon gas concentration in two sites on Mt. Etna to find correlations to volcanic and tectonic geophysical events. The results of our investigation allow us to characterize the fault systems in the two chosen sites. From our data a different behaviour is evident between the north-eastern and the south-western flanks. In particular our data exhibit: i) higher values in Vena then in Biancavilla station; ii) more fluctuating daily values in Biancavilla than in Vena; iii) opposite seasonal trends in the two sites. These results seem to exclude meteorological influence and suggest a link to different faulting mechanisms.

Even if the two fault systems lie in the same direction, at present the structural discontinuities near Biancavilla are typical of tectonic areas, while those near Vena have both tectonic and volcanic character, the latter being historically involved by eruptive events.

According to the literature, we confirm that radon anomalies are evident when seismic events occur at magnitudes higher than 3 . In fact, the most important result seems to be that of the 3rd November 2002 earthquake $\left(M_{d} 3.5\right)$ that affected a zone near the station and that followed a radon anomaly.

However, the occurrence of volcanic events during the observation period also suggests a possible correlation between radon concentration trend and eruptive activity of Mt. Etna. In the graph of fig. 4, an evident radon uprising can be observed during the seismic phenomena before and after the eruptive event, the same trend is also observed after the main seismic phase. Since the investigated period was characterized by high geodynamic activity, the increase in radon flow could be linked to both seismic and eruptive phenomena.

\section{REFERENCES}

Al-Hilal, M., M.R. Sbeinati and R. Darawcheh (1998): Radon variation and microearthquakes in Western Syria, Appl. Rad. Isot., 49 (1-2), 117-123.

AzZARO, R. (1999): Earthquake surface faulting at Mount Etna volcano (Sicily) and implications for active tectonics, J. Geodyn., 28, 193-213.

Barbano, S., M. Cosentino, G. Lombardo and G. Patanè (1980): Isoseismal maps of Calabra and Sicily earth- quakes (Southern-Italy), CNR-Progetto finalizzato geodinamica, Publication No. 341, pp. 116.

Benina, A., S. Imposa, S. Gresta and G. Patanè (1984): Studio macrosismico e strutturale di due terremoti tettonici avvenuti sul versante meridionale dell'Etna, in Atti III Convegno Annuale del GNGTS, 931-946.

Igarashi, G., S. SAEki, N. TAKahata, K. Sumikawa, S. TasaKa, Y. Sasaki, M. Takahashi and Y. Sano (1995): Ground-water radon anomaly before the Kobe earthquake in Japan, Science, 269, 60-61.

La Delfa, S., G. Patanè and C. Centamore (1999): The geodynamics of Mt. Etna volcano during and after the 1984 eruption, Ann. Geofis., 42 (3), 545-563.

Lo Giudice, E., G. Patanè, R. Rasì and R. Romano (1982): The structural framework of Mount Etna, Mem. Soc. Geol. It., 23, 125-158.

MonNin, M.M. and J. SEIDEL (1991): Radon and Volcanic Surveillance, in Radon Measurements by Etched Track Detectors, Application in Radiation Protection, Earth Science and the Environment, edited by A. SAEED DURRANI and I. RADOMIR, 274-285.

Montalto, A., S. Vinciguerra, S. Menza and G. Patanè (1996): Recent seismicity of Mount Etna: implications for flank instability, in Volcano Instability on the Earth and Other Planets, edited by W.C. MCGuIRE, A.P. JONES and J. Neuberg, Geol. Soc. Spec. Publ. 110, 169-177.

PATANÈ, G. and S. IMPOSA (Editors) (1995): Atlas of Isoseismal Maps of Etnean Earthquakes from 1971 to 1991 (Università degli Studi di Catania), pp. 89.

Patanè, G., A. Montalto, S. Imposa and S. Menza (1994): The role of regional tectonics, magma pressure and gravitational spreading in earthquakes of the eastern sector of Mt. Etna Volcano (Italy), J. Volcanol. Geotherm. Res., 61, 253-266

Patanè, G., G. Coco, M. Corrao, S. Imposa and A. MontalTO (1995): Source parameters of seismic events at Mount Etna Volcano, Italy, during the outburst of the 1991-1993 eruption, Phys. Earth Planet. Inter., 89, 149-162.

Patane, G., A. Montalto, S. Vinciguerra and J.C. Tanguy (1996): A model of the onset of the 1991-1993 eruption of Etna (Italy), Phys. Earth Planet. Inter, 97, 231-245.

PlaninIČ, J., V. RADOLIČ and Ž LAZANIN (2001): Temporal variation of radon in soil related to earthquakes, Appl. Rad. Isot., 55, 267-272.

RICHTER, C.F. (1958): Elementary Seismology (Freeman and Co., San Francisco, CA), pp. 768.

Romano, R. (Editor) (1982): Mount Etna Volcano: a review of recent earth sciences studies, Mem. Soc. Geol. It., 23, pp. 205.

Singh, M., R.C. Ramola, B. Singh, S. Singh and H.S. VIRK (1991): Radon anomalies: correlation with seismic activities in Northern India, in Radon Monitoring in $\mathrm{Ra}$ dioprotection, Environmental and/or Earth Science, edited by A. SAEEd DURRANI and I. RADOMIR, 354-375.

Vinciguerra, S., S. Garozzo, A. Montalto and G. Patanè (1999): Eruptive and seismic activity at Etna Volcano between 1977 and 1991, Volcanoes in the Quaternary, Geol. Soc., 161, 89-107.

VIRK, H.S. (1995): Radon monitoring of microseismicity in the Kangra and Chamba Valley of Himachal Pradesh, India, Nucl. Geophys., 9 (2), 141-146.

VIRK, H.S. and B. SINGH (1994): Radon recording of Uttarkashi earthquakes, Geophys. Res. Lett., 21 (8), 737-740. 